QUADERNS DE FILOSOFIA VOL. III NÚM. 2 (20I 6): 37-57

ISSN: 234I-I4I 4 eISSN: 234I-3042 DOI: IO.7203/QFIA.3.I.8269

Daniel Pallarés-Domínguez

Universitat Jaume I, Castelló

\title{
El potencial ético y educativo de la epigénesis proactiva en Kathinka Evers
}

Recibido: 3/6/16. Aceptado: 22/9/16

Resumen: La profesora Kathinka Evers es una de las coordinadoras del área filosófica relativa a la conciencia del Human Brain Project (HBP). Basándose en trabajos de neurociencia, biología y filosofía, su propuesta de epigénesis proactiva mantiene que existe una simbiogénesis cultural inevitable, en la que el ser humano está influido en su carácter y comportamiento por los genes de la misma forma en que con sus acciones y su comportamiento puede influir a la larga en las variaciones genéticas de generaciones posteriores. El objetivo de este trabajo es analizar su propuesta para dar cuenta de la importancia de la ética y la educación en el seno de la cultura, frente a las visiones más reduccionistas y materialistas de la neuroética.

Abstract: Professor Kathinka Evers is one of the coordinators of the philosophy area concerning consciousness of the Human Brain Project (HBP). Based on works in neuroscience, biology and philosophy, her proactive epigenesis proposal maintains that there is an inevitable cultural symbiogenesis in which genes have influence on human character and behavior in the same way as human actions and behavior can influence genetic variations in subsequent generations. The aim of this paper is to analyze this proposal in order to account for the importance of ethics and education in culture, and opposing more materialistic and reductionist views of neuroethics.

Palabras clave: epigénesis proactiva, simbiogénesis cultural, neuroética, ética. Keywords: proactive epigenesis, cultural simbiogenesis, neuroethics, ethics. 


\section{INTRODUCCIÓN}

L AS PROPUESTAS DE CARÁCTER REDUCCIONISTA Y MATERIALISTA que quieren ofrecer una explicación del comportamiento moral humano han tenido gran relevancia académica y científica dentro de la neuroética en los últimos años. Algunas de estas propuestas pretenden establecer, a partir de los datos neurocientíficos —especialmente a partir de los estudios con imágenes por resonancia magnética funcional (fMRI) — la primacía de la racionalidad consecuencialista frente a la deontológica (GREene 2008; GreEne et al. 2004), otras conciben la libertad como una ilusión del cerebro (RUBIA 2009; WEGNER 2002), y otras incluso intentan fundamentar la moral en el cerebro (MORA 2007; GazZaniga 2006; Moll et al. 2005). Contrariamente a esas propuestas, desde la perspectiva de este y otros trabajos (GArcía-Marzá y FeEnStra 20 i3; Pallarés-Domínguez 20I3; Cortina 20I2), creemos que las neurociencias tienen una gran importancia a la hora de estudiar el comportamiento humano, especialmente el moral, siempre y cuando, a través de un verdadero diálogo interdisciplinar con la filosofía moral, reconozcan hasta dónde pueden llegar en dicho estudio. Y es que precisamente, como ya advirtió A. Cortina, las neurociencias pueden aportar un estudio sobre las bases neurofisiológicas del comportamiento moral, pero no derivar de ellas los contenidos de la dimensión moral (CoRTina 20 i i, 94).

Por ello, es interesante estudiar aquellas propuestas neuroéticas que sí promuevan un trabajo interdisciplinar entre neurociencia y filosofía, sin que ello comporte un intento de colonización de la primera sobre la segunda, a pesar del empeño de algunos en esta colonización (RAMACHANDran 2008). En este sentido, la propuesta de K. Evers puede ayudar a este estudio interdisciplinar y dialógico, reconociendo la interdependencia mutua que existe entre el medio ambiente y la cultura con los genes del ser humano (Evers 2005; 2007; 20I0; 2015).

Así, desde una perspectiva realista y de pleno compromiso con el ser humano desde el punto de vista ético, K. Evers destaca en su teoría el aprendizaje cultural en relación con la huella genética. El elemento clave, se puede adelantar ya, no será solamente la huella epigenética almacenada en nuestros cerebros, sino la posibilidad de, pese a que esto pueda ser así desde el punto de vista neurobiológico, cambiar esa huella para las generaciones futuras. Pero no por una mejora neurobiológica al modo de los psicofármacos, como algunos han malentendido (SCHLEIM 20 I 5, 2), sino por una mejora en el comportamiento del ser humano desde el punto de vista educativo y ético, que exprese un compromiso moral con los demás. Y esto es algo que solo se conseguirá con el aprendizaje moral. 
Este trabajo pretende dar cuenta de su propuesta mediante una metodología argumentativa y crítica, y se dividirá en las siguientes partes. En primer lugar se analizarán los presupuestos de los que parte la epigénesis proactiva, especialmente el materialismo ilustrado. En segundo lugar, se explicarán las tendencias preferenciales del ser humano, que le caracterizan como un ser preferente y evaluador, rasgo esencial para determinar su huella genética. En tercer lugar, se analizarán algunos inconvenientes que plantea y se dará cuenta de la responsabilidad naturalista que posee el ser humano como un posible elemento motivador para el comportamiento moral a la altura de una sociedad pluralista. También, complementariamente a la vertiente teórica, se indicarán algunas propuestas prácticas de la aplicación de la epigénesis proactiva.

\section{El marco CONCEPTUAL DEL MATERIALISMo ilustrado}

Para entender la epigénesis proactiva, es preciso estudiar previamente el marco conceptual del materialismo ilustrado del que parte K. Evers. Pues su teoría no se trata solamente de un mecanismo de transmisión genética, sino que implica una concepción del cerebro humano, un concepto antropológico — como ser humano libre y autónomo- y una reconsideración de la filosofía de la ciencia.

A juicio de K. Evers, las teorías científicas de la naturaleza y las ciencias del espíritu se pervirtieron durante los siglos XIx y xx, especialmente porque cayeron víctimas de la psicofobia, lo que se tornó en un eliminativismo y cognitivismo ingenuos:

La ciencia ignoró igualmente durante largo tiempo dos aspectos importantes del espíritu que sin embargo son esenciales para comprender el desarrollo de la conciencia por el cerebro y la propensión de este último al juicio moral; y también puede verse en esta exclusión teórica una forma de psicofobia: se trata de la arquitectura del cerebro biológico, y de la emotividad que le es inherente (EVERS 20IO, 57-8)

Pero ¿por qué querría el ser humano estudiar las ciencias del espíritu eliminando las emociones y la conciencia? Las causas que identifican algunos autores parecen ser por un lado la dificultad del estudio de las emociones y la conciencia (LeDoux 1999) y también el miedo a las pasiones incontroladas que históricamente han causado enormes daños, ya sea en forma de fervor religioso o de fanatismo político (EVERS 20 Io, 67). Estas pasiones incontroladas que generan en ocasiones las emociones fueron tomadas como algo negativo, lo que desembocó también en una concepción antropológica negativa. 
Por ejemplo, A. Koestler describió en The ghost in the machine (1989) las catástrofes y los horrores a los que puede conducir la capacidad de destrucción masiva del ser humano, concluyendo que tenemos por naturaleza una inclinación violenta y autodestructiva. Del mismo modo, K. Lorenz expone:

Por razones fáciles de comprender, el hombre está particularmente opuesto a los nefastos efectos de la selección intraespecífica. Como ningún otro ser antes de él, ha sabido domeñar a todas las potencias hostiles del medio extraespecífico. Ha erradicado al lobo y el oso, y ahora es él su propio enemigo, de acuerdo con el dicho romano: homo homini lupus.

Apenas llegó el hombre a dominar en cierto modo, gracias a sus armas, sus vestimentas y su organización social los peligros externos del hambre, el frío y las fieras devoradoras, que ya no fueron factores esenciales en la selección, intervino sin duda una selección intraespecífica perjudicial. El factor selectivo fue a partir de entonces la guerra que se hacían entre sí las hordas vecinas de gentes hostiles (1992, 53-4)

La antropología negativa que se sigue de autores como K. Lorenz y A. Koestler desde el punto de vista biológico y evolutivo está en la misma línea de autores como T. Hobbes o N. Maquiavelo en filosofía política, y lleva a comprender al ser humano como un maximizador de su beneficio y de su interés individual, como expone críticamente A. Cortina (2007, 61). La influencia que ha tenido esta concepción antropológica negativa desde ámbitos tan diversos como la biología evolutiva o la filosofía política, ha tenido un calado muy hondo en las neurociencias, especialmente en la neuroética (SANGUINETI 20I4; 20I 2).

Desde esta concepción de ser humano negativa, en la que las emociones deben expulsarse porque conducen precisamente a pasiones que nos pueden destruir, gran parte de la neurociencia y la neuroética entenderán que la obligación moral es un instrumento al servicio de intereses "premorales", tales como mantener la vida y reconocer al cercano (ChURChland 20I2). Con lo cual, se perpetuará la creencia de que no hay más razón para ser justos que la de maximizar la supervivencia, cosa que es claramente un error, como advierte A. Cortina $(2007,67)$.

Los autores a los que K. Evers se refiere son los que ella toma principalmente para establecer su teoría de la epigénesis proactiva a partir del materialismo ilustrado, entre los cuales destacan: Jean-Pierre Changeux (2004), Stanislas Dehaene (Dehaene y Changeux i 989; Dehaene et al. 2006; Dehaene et al. 2003; Dehaene et al. 1 998), Gerald Edelman (1992) y Joseph Ledoux (1999). Para no repetir los errores del pasado en forma de eliminativismo y cognitivismo ingenuos, psicofobia y desvío ideológico, la neuroética debe construirse bajo los fundamentos del materialismo ilustrado (Evers 20 io, 69). 
El materialismo ilustrado fue un término originariamente utilizado en química (BACHELARD I953) y fue exportado o extendido al ámbito neurocientífico por J.-P. Changeux (2004) para hablar de la caracterización de un cerebro humano que se oponía al reduccionismo. Concebido originariamente como "materialismo racional", denominado más tarde como "informed materialism" (Evers 2007, 48) y finalmente como "materialismo ilustrado", lo importante es la idea que subyace a esta teoría. Y es que sin negar la base fisicoquímica de los procesos celulares elementales del cerebro humano, afirma que la conciencia es, evolutivamente, una función biológica de las actividades neuronales, pero que precisamente por eso convierte al cerebro en un órgano narrativo y proyectivo, variable y activo de forma autónoma que necesita de las emociones como "coerciones necesarias" (Evers 2010, 69; 2007, 48). El materialismo ilustrado se articula en torno a cuatro pilares fundamentales.

En primer lugar, la conciencia que, bajo una concepción evolucionista, forma parte ineludible de la realidad biológica del ser humano.

En segundo lugar, el estudio de la experiencia consciente no solo a través de la información subjetiva por autorreflexión, sino también mediante las observaciones neurofisiológicas que pueda proporcionar la neuroética.

En tercer lugar, una concepción del cerebro humano como un órgano plástico, proyectivo y narrativo que faculta al ser humano para actuar de manera autónoma y libre, y está sometido a la acción resultante de una simbiosis sociocultural-biológica.

En cuarto y último lugar, la emoción como rasgo distintivo de la conciencia: "Las emociones hicieron que se despierte la materia y le permitieron producir un espíritu dinámico, flexible y abierto; según la imagen que da de ella el materialismo ilustrado, la persona neuronal está verdaderamente despierta, en el sentido más profundo del término" (Evers 20 io, 15). Tal y como observa J. LeDoux (1999, 19), la red de conexiones que relacionan los sistemas emocionales con los sistemas cognitivos son más fuertes que a la inversa. Pero teniendo en cuenta la epigénesis proactiva, puede que esto cambie en el futuro, de forma que las conexiones entre el córtex prefrontal y la amígdala — que son muy fuertes en los humanos- se acrecienten. Así, de forma optimista, J. LeDoux expone que en el futuro estas relaciones podrían acrecentarse de forma que el córtex prefrontal gane terreno en el control de las emociones. Y de forma todavía más optimista destaca la posibilidad de que se llegue a una síntesis armónica, un equilibrio entre las razones y las pasiones, entre la conectividad de la amígdala con la corteza prefrontal. ${ }^{1}$

\footnotetext{
${ }^{1}$ Hay que tener en cuenta que J. LeDoux no cree en el sistema límbico como conjunto
} de estructuras. Alude a que su nombre es una creación que no refleja realmente las funciones 
Todos los supuestos anteriores hacen referencia a que el materialismo ilustrado es, en su base, una concepción del cerebro humano. Pero esta concepción repercutirá tanto en el conocimiento de la experiencia subjetiva humana como de los mecanismos fisiológicos y filosóficos por los cuales podemos acceder al estudio de esta (Dehaene et al. 2003; Evers 2007, 48). En esta concepción del cerebro, la conciencia y la emoción son los dos elementos esenciales que se configuran a través de la evolución pero se reformulan a través de la plasticidad cerebral (Lipina 20I4, 71-3).

Teniendo en cuenta los cuatro pilares básicos del materialismo ilustrado, K. Evers apuntará que el ser humano es un "evaluador nato" (Evers 20Io, 113-7; 201 5, 2-6), es decir, posee una capacidad innata para evaluar consciente y emocionalmente, que condiciona la base misma de la capacidad moral. Esta capacidad para evaluar condicionará la capacidad para preferir y escoger entre diversos cursos de acción que determinarán la huella epigenética que se transmitirá con el tiempo, en un proceso de relación simbiótica con la cultura y el ambiente que la autora denomina epigénesis proactiva. Esta capacidad de evaluar y preferir es por tanto una de las claves de su teoría, y responde a una serie de tendencias preferenciales.

\section{LAS TENDENCIAS PREFERENCIALES INNATAS DEL CEREBRO}

Anteriormente se ha dado cuenta de que las ideas básicas del materialismo ilustrado conforme al cerebro humano permiten caracterizarlo como un órgano proyectivo y narrativo, que posibilita la autonomía y libertad del ser humano. Esta propuesta está lejos de aquellas que, en neuroética, apuntaban desde una perspectiva reduccionista y materialista a la ilusión de la libertad humana por ser una ficción del cerebro (RUBiA 2009; WeGNeR 2002).

Teniendo en cuenta los elementos fundamentales destacados anteriormente, el materialismo ilustrado apunta a que: no se puede comprender el espíritu sin apelar a la biología; la conciencia es irreducible a la realidad biológica; el cerebro es selectivo emocionalmente, por lo que los valores son incorporados como coerciones necesarias. Por tanto "la evaluación resulta ser un rasgo fundamental del cerebro así concebido" (Evers 20 io, 114). Es decir, los procesos de evaluación y el sistema emocional son los principales condicionantes de una

estructurales a las cuales hace referencia. Quizá esto influya en la búsqueda de la síntesis armónica, pues parece más viable si se difumina conceptualmente la principal zona que gestiona las emociones en la tradición neurológica que arranca con Franz Joseph Gall, sigue con Walter Cannon y Phillip Bard, James Papez y llega a Paul McLean (LeDoux I999, 74-101). 
característica básica de nuestros cerebros, la capacidad de valorar y por tanto de evaluar. ${ }^{2}$

Bajo esta concepción, la noción de "valor" no dista mucho de lo que entiende A. Cortina en Ética de la razón cordial (CoRTINA 2007), especialmente por su fuerza motivadora y su resultante importancia para el aprendizaje moral. Pero a diferencia de A. Cortina, K. Evers no proporciona la respuesta sobre en qué valores hay que educar. En cambio la primera autora sí que apunta al "reconocimiento cordial” como núcleo fundamental de las exigencias de justicia, y señala además que la educación moral debe tener como ejes fundamentales: (I) el eje del conocimiento —habilidades más conocimientos para conseguir metas-; (II) el eje de la prudencia; y (III) el eje de la sabiduría moral que cuente con la justicia y gratitud.

Pues si K. Evers apunta que los valores y las emociones son "rasgos fundamentales del cerebro activo de forma autónoma", y que "tenemos una predisposición neurobiológica para desarrollar sistemas de valores complejos y variados, sobre todo de valores morales, que nos permite funcionar en nuestros entornos físico, social y cultural" (Evers 20Io, 115), pero no nos dice cuáles debemos destacar en la educación, la verdad es que nos dice bien poco. Pero lo más importante es que desde una perspectiva neurobiológica apunta a que la capacidad de emitir juicios morales — a partir de valores y de la capacidad evaluativa- y de elegir libre y responsablemente tiene un sentido lógico, práctico y biológico (Evers 20 io, 116).

Siguiendo con el pensamiento de K. Evers, el hecho de que hayamos nacido como seres evaluadores por naturaleza, nos predispone a desarrollar una serie de tendencias evaluativas que son universales: a) el interés por el "sí mismo"; b) el control sobre el entorno inmediato; c) la capacidad disociativa; y d) el interés por los otros en forma de simpatía selectiva o xenofobia empática (Evers 2015, 1; 2010, 121).

En cuanto a la primera de estas tendencias preferenciales (a), K. Evers entiende que la moralidad es un fenómeno social que se ha desarrollado en contextos de comunicación e interacción. Para poder participar de ella son necesarias comunicaciones e interacciones evolucionadas y, a su vez, para que sean evolucionadas, necesitan de la exigencia de sus seres de ser "sí mismos". Ser "sí mismo" significa que el sujeto sea consciente de que es un sujeto de experiencia y, en segundo lugar, que sea capaz de diferenciar entre él mismo y

\footnotetext{
${ }^{2}$ Basándose en los trabajos de S. Dehaene y J.-P. Changeux (I99I, I989) y de G. M. Edelman (I992), K. Evers apunta que la evaluación no solo es el rasgo fundamental del cerebro, sino del aprendizaje, que viene a ser en términos neurales la modificación del comportamiento que resulta cuando el cerebro categoriza los estímulos en términos de valores positivos o negativos.
} 
otros objetos. En definitiva, el rasgo característico del "ser sí mismo" es la conciencia, tanto de uno mismo como de los demás (Evers 20I0, 117).

La segunda de las tendencias preferenciales (b), expresa que el cerebro humano está no solo diseñado, sino comprometido con la producción de imágenes con referencia a su entorno, esto es, con intencionalidad (CHANGeux 2004; EdeLMAN 1992, 112). Además, somete a prueba los modelos que crea, perpetuando aquellos que funcionan y le permiten sobrevivir mejor. Pero el cerebro no solo está programado para la creación de imágenes de un modo intencional, sino que además las imágenes que crea son programadas en un orden; esto es, tiene capacidad organizativa (Evers 20Io, 82).

La disociación es la tercera tendencia preferencial innata del cerebro (c). Esto hace al ser humano un animal disociativo; es decir, que gastamos muchos recursos y energías intelectuales y emocionales en alejarnos de cosas que no queremos o que tememos (Evers 2010, 122). Queremos disociarnos de lo biológico para trascenderlo y, en ese objetivo, muchas veces hemos confundido nuestra inteligencia con la trascendencia biológica (Evers 20 I0, 124).

A partir de los trabajos de J. Decety (2007) y P. Ricoeur (I 992), K. Evers establece una cuarta tendencia preferencial innata del cerebro (d), el interés por los otros (Evers 201 5, 4-6; 2010,125 ; 2007, 50). Como animales sociales, el interés por uno mismo es la fuente del interés por otros, principalmente por aquellos con los que estamos en relación y nos identificamos. De esta tendencia preferencial es de donde surge en gran parte la ética.

Dadas las características de evaluadores y disociadores, y a partir de estudios de neurobiología de la empatía (JACKSON et al. 2006; SINGER et al. 2004; IACOBINI et al. 2005), K. Evers establece que la empatía y la simpatía están involucradas en las funciones cognitivas complejas sometidas a variaciones tanto biológicas como socioculturales (Evers 20 I 5, 5). Estas variaciones producen que el ser humano sea un xenófobo empático natural:

Somos empáticos en virtud de nuestra comprensión de un conjunto relativamente grande de criaturas; pero somos simpáticos de manera mucho más estrecha y selectiva hacia el grupo restringido en el que nacimos o al que hemos elegido unirnos, mientras que, por otro lado, tendemos a permanecer indiferentes o antipáticos hacia todos los otros, y neutros u hostiles hacia la mayoría de extranjeros (Evers 20IO, 132)

Según estas palabras, si somos xenófobos empáticos ¿qué nos impide no ser un homo homini lupus y buscar la maximización del propio interés y la supervivencia individual? ¿Se pueden desarrollar actitudes globales como el caso de los Derechos Humanos, o estas declaraciones universales son abstractas en virtud 
de que estamos neurobiológicamente condicionados para ser simpáticos con el propio grupo y muy selectivos y limitados para con los extrańos? (Evers 20Io, 133). Lo que nos va a impedir concebir al ser humano solamente de este modo es el estudio del último eslabón de la teoría de K. Evers: la epigénesis proactiva.

\section{ANÁlisis y CRÍtiCA DE LA EPIGÉNESIS PROACTIVA}

Afirmar que el ser humano es un xenófobo empático no significa que deba ser así o que no pueda cambiar. Y si además tenemos en cuenta el proceso de epigénesis neuronal, el camino parece más viable. Por ello, desde el materialismo ilustrado, que expone que la cultura y la naturaleza se hallan relacionadas simbióticamente y se influyen causalmente, puede que la arquitectura de nuestros cerebros determine quiénes somos y el tipo de sociedades que desarrollamos. Pero además:

Nuestras estructuras sociales también tienen un fuerte impacto sobre la arquitectura del cerebro, en particular a través de la huella cultural que está allí epigenéticamente almacenada. El camino, por consiguiente, está abierto para que seamos proactivos desde el punto de vista epigenético (Evers 2010, 136)

Lo que se conoce como epigénesis neuronal, que más tarde se expresará como "epigénesis proactiva" (Evers, 2015) significa precisamente esta doble determinación del cerebro a través de las estructuras sociales y de las estructuras sociales por nuestras acciones debido a las huellas genéticas. Se trata sin duda de un doble proceso que ya se da debido a las tendencias preferenciales anteriormente comentadas.

La epigénesis proactiva no se trata en ningún caso de una intervención en el cerebro humano ni de un mejoramiento cerebral a base de psicofármacos o nootropos como algunos creen (SCHLEIM 2015 , 2). Por el contrario, se trata de modificar o adaptar las estructuras e instituciones sociales para beneficiarnos de acuerdo con la arquitectura neural de nuestros cerebros. Por tanto, se entiende la epigénesis como la transmisión genética de los rasgos fenotípicos, es decir, la transmisión genética de los rasgos heredados de la conjunción de un ser con su medio ambiente. En el caso del ser humano, el ambiente incluye la cultura, por lo que la epigénesis sería la transmisión genética de los rasgos fenotípicos — proporcionados por el medio ambiente en conjunción con la cultura-.

El término epigénesis en biología fue acuñado en primer lugar por W. Harvey en 1651, pero es en el sentido que siglos más tarde señaló C. Waddington 
(1942) en el que se suele entender, es decir, en la relación entre los genes y sus entornos para producir un fenotipo, aunque en el caso de la teoría de K. Evers aplicado además a las redes neurales. En otras palabras, la epigénesis proactiva se refiere a la epigénesis de las redes neurales por estabilización de la sinapsis, de acuerdo con la cual el ambiente-cultura afecta a la organización de las conexiones en un envoltorio de redes neurales a través de la estabilización o eliminación de sinapsis lábiles, todo ello bajo el control de la actividad global de las redes neurales (Evers 2015, 6-7). Este modelo fue denominado en un primer momento por J.-P. Changeux "teorema de la variabilidad" (ChAngeux et al. 1973).

La epigénesis de las redes neuronales a través de la estabilización de la sinapsis da paso a la selección de los circuitos culturales y a la transmisión de las huellas culturales epigenéticas (Evers 20 I 5, 6-9; Changeux y DANChin 1976). Esto quiere decir que las huellas culturales son una realidad física en el cerebro humano, dejan una huella física que tiene mucha importancia en el periodo postnatal de desarrollo y educación. Las huellas culturales epigenéticamente almacenadas en nuestros cerebros juegan un papel muy importante en la organización del fenotipo cerebral en relación con el grupo social a través de mecanismos como: el lenguaje y la escritura, las tradiciones y los sistemas simbólicos, y también las normas éticas y sociales (Evers 20 i 5, 9).

Con todo, cabría señalar como mínimo tres dificultades que plantea en principio la teoría de la epigénesis proactiva.

En primer lugar (I), la debilidad de un razonamiento circular. Siguiendo con el razonamiento de K. Evers, si hasta ahora el ser humano ha evolucionado como xenófobo empático, es debido en gran parte a la huella epigenética cultural que se almacena en nuestros cerebros, ¿no podría ser posible la influencia inversa? Es decir, ¿no sería posible que la cultura y las instituciones sociales que creamos puedan ayudarnos a mejorar biológicamente y a evolucionar para volvernos seres humanos simpáticos y no solo empáticos xenófobos? (Evers 20 io, 141). ¿Deberíamos ser primero seres ya no xenófobos empáticos y no violentos para que una sociedad con tales características pudiera ser mantenida? $Y$ además existe otra incógnita, la pregunta sobre el tiempo, que tampoco despeja la autora: “¿Cuánto tiempo debe pasar para que una característica cultural deje una huella cerebral?” (Evers 20 I 5, 14; Evers 2010, 142). La autora no aclara este punto.

En segundo lugar (II), los principios puente entre el nivel material al estudiar las neuronas y el nivel cognitivo al hablar de la mente. A este respecto, la autora expresa:

La fuerza motriz no disociativa del materialismo ilustrado consiste en buscar principios-puente que unan diferentes niveles de explicación y diferentes tipos de 
conocimientos sobre el espíritu y el cerebro humanos, y que unifiquen nuestra comprensión de la conciencia como una función del cerebro cuyo desarrollo y funcionamiento se efectúan en un entorno natural, social y cultural (Evers 20I0, 125)

¿De qué tipo serían esos principios puentes? ¿Darían cuenta de la dimensión material de las neuronas, o de la dimensión cultural? ¿Se referirían a los mapas del cerebro o a los mapas de pensamiento? ¿Se admitiría con ellos un dualismo o se desprendería de ellos un monismo materialista? La forma en cómo sean estos principios puente puede condicionar claramente la teoría de K. Evers. Es un poco parecido al problema que ya se le presentó a S. Freud en 1895 con su obra Proyecto de una psicología para neurólogos, en lo referente al puente entre la neurona y la dimensión simbólica del lenguaje (BIDON-CHANAL I996, 260; Freud i99i), y que sin duda retoma J.-P. Changeux (i 986, 168) en su intento de eliminar las barreras que separan lo neural de lo mental y construir un puente por el que podamos pasar de uno a otro.

El monismo materialista o reduccionismo materialista ha sido una de las posiciones más comunes en gran parte de la neuroética, y otras neurociencias sociales, hasta el momento. Esta posición ha llevado a muchos autores, por ejemplo, a intentar fundamentar la moral únicamente desde el cerebro, en diversos aspectos. Entre ellos, se podrían destacar, la creencia de una "red neural de la moralidad", formada por varias áreas. Por un lado, la corteza prefrontal ventromedial (CPFvm) que se encargaría de dotar a los estímulos externos de un valor socioemocional y de inhibir las respuestas instintivas de otras áreas. Por otro lado, la corteza orbitofrontal, que inhibiría las respuestas automáticas y rápidas especialmente de la amígdala. Por último, la amígdala, que se involucraría en el aprendizaje moral y las respuestas hacia las amenazas (Torralva y Manes 20i4, 32; Mendez 2006; Moll et al. 2005).

Otros autores, por ejemplo, a partir de este reduccionismo materialista, han derivado una naturalización de la moral que les ha llevado a postular "fenómenos reguladores sociales de origen natural". La mayoría de autores en esta línea coinciden en que estos son: el compartir comida, la reciprocidad en sus distintas modalidades, la asistencia mutua, la justicia retributiva, la reconciliación, o la mediación del conflicto (CELA-Conde 2005, 11; Flack y DE WAAL 2000). Al parecer, estas características implican una especie de sentido moral que justificaría la naturalización de la ética en el cerebro.

Estos son solo algunos ejemplos que ejemplifican el reduccionismo materialista en el terreno neuroético. $\mathrm{Y}$ es que asumir que mente y cerebro son un mismo elemento puede tener implicaciones problemáticas para el estudio interdisciplinar de la neurociencia y la ética. La principal de estas implicaciones 
es el intento de estudiar la totalidad conforme a la base biológica y material, como se ha visto en los ejemplos anteriores. Por tanto, lo interesante para un verdadero estudio interdisciplinar sería estudiar mente y cerebro conjuntamente, pero no identificándolos como un solo elemento. Ciertas teorías permiten esta premisa, como por ejemplo el dualismo interaccionista dentro del emergentismo. Algunos autores señalan que el emergentismo podría suponer una posición ampliamente aceptada entre filósofos y neurocientíficos que trabajan en el terreno neuroético, aunque en ocasiones no se entienda de un modo correcto (Gracia 2013, 557).

Lo interesante del emergentismo en este sentido, sería la aplicación a las propiedades sistémicas nuevas que surgen de la mente humana (SPERRY I980, 195). Dichas propiedades son trascendentales porque van más allá, superan lo inmanente del propio medio natural y lo revalorizan como otra cosa. Es lo que se ha dado en llamar, por ejemplo desde el dualismo interaccionista de K. Popper, mundo de la cultura o mundo del espíritu. En palabras de D. Gracia (2013, 557): "permite trascender el 'medio' propio de cualquier especie animal hasta convertirlo en 'mundo'”. En efecto, K. Popper apuesta por la autonomía del Mundo 3, pero sin negar su trasfondo biológico y evolutivo (Popper y EcCles I993; Popper 1997, 60-1). Es en la realidad del Mundo 3 donde reside la importancia ética y educativa de su propuesta. Los objetos del Mundo 3 son reales porque en nuestra interacción mutua con ellos podemos utilizarlos para cambiar el mundo (Popper I997, 88).

Dentro del campo neuroético, una de las grandes preguntas que el emergentismo debería hacerse es: ¿cómo es posible que el ser humano en su relación biológica pueda construir sistemas de orden superior como la ética y la educación? Y, además, ¿̨cómo es posible si esos sistemas de orden superior están compuestos por elementos emergentes que no se reducen a los individuos que los conforman ni a sus cerebros? (GIBERT y CoRREA 200 I, 175). Desde las ciencias de la complejidad, la respuesta a estas preguntas ha venido en parte dada por la propuesta autopoiética de H. Maturana, que busca los principios constitutivos de los fenómenos sociales en la estructura y organización de los seres vivos a partir de las bases celulares, haciendo una abstracción de los fenómenos.

El concepto de autopoiesis ha tenido un importante impacto en las teorías del pensamiento complejo. Quizá en parte debido a la figura de $\mathrm{H}$. Maturana, que a pesar de ser biólogo, ha ido adquiriendo un determinado renombre en las neurociencias (Pedrol Troitero 2009, 334). En su origen, la autopoiesis supone que un sistema vivo está organizado de una forma determinada mediante la cual se autoproporciona los procesos y componentes que necesita a partir de los mismos procesos y componentes que posee. En un primer momento, la autopoiesis designa un sistema de organización propio de 
la biología de los seres vivos — biótico—, pero en un segundo momento implica un sistema de conocimiento de la realidad acorde al primero — vital-. En este sentido, para H. Maturana y F. Varela (I984), el paradigma del monismo materialista que reduce todo al sentido biológico —en algunos casos de la neuroética, por ejemplo- no tendría cabida.

Si no se define el carácter de esos principios puente, existe el riesgo de caer en un monismo materialista. ¿̇Acepta el materialismo ilustrado la multiplicidad de la materia, o más bien la unifica con la conciencia del cerebro en cuanto a la función del mismo? Esto puede ser problemático en caso de que no se aclare. Como expone J. C. Tealdi:

Pero también necesitamos definir el género de esos puentes o interfaces porque, a menos que los reduzcamos a un único género que sea a la vez corpóreo, incorpóreo y abstracto, con un monismo que niegue la pluralidad de la materia y su discontinuidad irreductible, les deberemos adjudicar uno u otro de esos géneros $(2012,3)$

Por tanto, teniendo en cuenta estas palabras, la neuroética que se postula desde el materialismo ilustrado debería justificar si los principios puente entre las neurociencias y la ética son algo más que un intento de proponer una adecuación entre enunciados del campo de la ética y del campo de las neurociencias. Si realmente las neurociencias tienen una pertinencia normativa, ¿̨ómo se puede pasar del ámbito prerreflexivo y natural de la selección sináptica al ámbito reflexivo de la legitimación de las normas éticas? Si no se da respuesta a esta pregunta, se corre el riesgo de caer en un monismo materialista al modo del positivismo comptiano. Si se supone, como dice K. Evers que la materia "se despierta", antes de intentar pasar de las teorías científicas a las teorías éticas, sería de importancia capital justificar el paso de la materia a la conciencia (Tealdi 20i 2, 7-8).

En tercer lugar (III), existe el riesgo de caer en la falacia naturalista. Lo cierto es que K. Evers dedica un gran esfuerzo a justificar que ni el materialismo ilustrado ni la epigénesis proactiva caen en la falacia naturalista (Evers 20I5, 12-6; Evers 20 Io, 145-50). Para ello, realiza un análisis filosófico e histórico que arranca desde el sofisma naturalista de George E. Moore hasta Richard M. Hare. El llamado "sofismo naturalista" hace referencia a la expresión acuñada por G. E. Moore según la cual se identifica el bien con otras propiedades tales como la utilidad, el placer o la felicidad, o incluso a la reducción del bien a tales propiedades. Contra tal tesis, G. E. Moore mantiene la objeción del "argumento de la cuestión abierta", según la cual un término evaluativo no puede ser definido como equivalente a los criterios de su propia aplicación (Moore 1978). 
Existen otras interpretaciones del sofisma naturalista que son más directamente pertinentes a la neuroética, en concreto la formulada por R. M. Hare (1975), según la cual, consiste en derivar un "debe" a partir de un "es", y conceder que las propiedades descriptivas implican propiedades normativas. Pero hay que tener en cuenta que ni el materialismo ilustrado ni la epigénesis proactiva caen en la falacia naturalista:

Por ejemplo: aunque supongamos que algunas tendencias evaluativas son innatas en la arquitectura del cerebro humano normal, tales como el interés por uno y la simpatía selectiva, este hecho (si es tal) a propósito de la estructura neuronal del ser humano implicaría, hay que estar de acuerdo en esto, que cada individuo de buena salud y suficientemente maduro experimentaría en cierta medida a la vez interés por sí mismo y simpatía por otras criaturas. Sin embargo, no es la implicación de una norma sino la implicación empírica de otro hecho. Esto no implica que esté bien (o mal), ni que deberíamos concebir como bien (o mal) el hecho de que estamos así constituidos (Evers, 20 Io, 147)

Teniendo en cuenta estas palabras, hay que señalar que, a diferencia de las teorías que partiendo del mismo hecho - ser humano como xenófobo empático y evaluador innato-, como la de P. S. Churchland, y que caían en la falacia naturalista, la teoría de K. Evers no comete este error. El materialismo ilustrado no concluye que por el hecho de que estemos así constituidos, se deban derivar normas de que nos comportemos de acuerdo con estos hechos. Más bien al contrario, la epigénesis proactiva plantea la posibilidad de que, con la educación y la influencia en una huella epigenética en generaciones futuras, se pueda cambiar este hecho. El problema es que no nos dice el cómo ni cuándo.

Aunque pueda parecer que la falacia naturalista no sea un tema interesante actual de discusión en ética, lo cierto es que se ha puesto de manifiesto nuevamente desde la neuroética en la última década. Si bien es cierto que desde el punto de vista de las éticas normativas, se ha estudiado y tratado ampliamente la diferencia entre lo descriptivo y lo normativo (GómEZ 2007, 45-6) la pretensión de normatividad — no solo científica sino también éti$\mathrm{ca}$ - de gran parte de la neurociencia, sigue estimando que las condiciones de verdad de los enunciados morales son parecidos a los de las ciencias naturales empíricas.

En efecto, la falacia naturalista se ha vuelto a poner de manifiesto con las afirmaciones de diversos autores. Por ejemplo, concluyendo solamente a partir de la observación empírica del cerebro que los seres humanos estamos fraguados a nivel neural para desarrollar una conducta que nos impulsa a estar bien 
con los cercanos, mantener posiciones de respeto y tolerancia para maximizar nuestro interés en la supervivencia y el bienestar (CHURCHLAND 2O I 2); que no existe la libre voluntad humana porque es el cerebro el que toma la decisión antes que nosotros - malinterpretando los experimentos de B. Libet- de tal forma que a lo sumo podría solo existir una ilusión de libertad humana que nos ayudaría a convivir socialmente (Wegner 2002; RUBIA 2009); y que el modelo de referencia para la educación moral debe ser el del intuicionismo social (Haidt 200I) y no el del desarrollo del juicio moral a través de la capacidad de dar razones —impulsado principalmente a través de L. Kohlberg-.

La propuesta de K. Evers se aleja de estas posiciones y no incurre en la falacia naturalista. Contrariamente a los ejemplos anteriores, a pesar de que podamos estar cerebralmente constituidos de tal forma, esto no implica que no podamos cambiar - de hecho, no hay que olvidar que gran parte del cerebro humano tiene una enorme plasticidad neural-.

Sin embargo, a pesar de que no se puede derivar un "debe" a partir de un "es" conforme a los parámetros neurales por los que estamos fraguados hoy en día, es una responsabilidad humana atender a esos principios puente en la conexión entre lo neurobiológico y lo histórico-cultural. La forma de atender a ellos es descubrir su relación con las normas morales de un determinado momento de la historia para que, estudiándolas, podamos saber cómo llegaron a formarse (Evers 20 IO, 148), y dicho estudio haga más cercano ese cuándo que se ha anunciado en el párrafo anterior. Por eso K. Evers afirma que la falacia naturalista se transforma así en una "responsabilidad naturalista": la responsabilidad de que a través de la conexión de hechos y valores, lo biológico y lo sociocultural, podamos usar ese conocimiento en beneficio de nosotros mismos y nuestras sociedades. Esta responsabilidad naturalista puede constituir un elemento motivador para un comportamiento moral que, en el seno de una sociedad pluralista, busque las exigencias de justicia universalizables para los seres humanos.

Con todo, la epigénesis proactiva no solo responde a una propuesta teórica, sino que ya se está adoptando como base para propuestas que exceden la tradición neurocientífica francesa con la que se inicia, y que intentan responder a demandas de justicia ética de carácter universal. Concretamente estas propuestas se han plasmado a través de una serie de programas sobre neurociencia cognitiva y del desarrollo, que estudian cómo la pobreza infantil condiciona el desarrollo cognitivo. Estos programas se han dado en Argentina especialmente en los últimos cinco años (Lipina y Segretin 20 I 5, 113; Lipina 20I4).

Los estudios neurocientíficos sobre la pobreza infantil en la última década han concluido que las carencias, tanto materiales como simbólicas desde el nacimiento, limitan no solo las oportunidades de desarrollo sino también la 
inclusión social durante toda la vida. ${ }^{3}$ Las conclusiones de estos estudios indican que el impacto de la carencia de condiciones de vida que consideramos dignas deja una huella neural epigenética que no es homogénea ni afecta a las personas en el mismo momento en el que tiene lugar el estado de pobreza, pues puede manifestarse a lo largo de toda la vida (Lipina y Segretin 20 I 5,112 ).

Es decir, la pobreza afecta realmente a la configuración y regulación funcional del sistema nervioso a diferentes niveles — molecular, hormonal, activación neural, autorregulación y conducta - y puede tener efectos programáticos durante toda la vida. Teniendo en cuenta no solo lo estudiado de la autopoiesis sino también de la epigénesis proactiva, desde una perspectiva neurocientífica, la pobreza implicaría "la corporalización neural de factores biológicos, psicológicos, sociales y ambientales, en un contexto de cambio dinámico continuo" (Lipina y Segretin 20 I 5,113 ).

Entre las propuestas neuroeducativas para intentar paliar este impacto se pueden destacar especialmente las de la ciudad de Buenos Aires. ${ }^{4}$ Todas estas propuestas irían enfocadas a potenciar, mediante entrenamiento, los procesos cognitivos centrales en el desarrollo cognitivo y socioemocional de los infantes que están privados de un primer aprendizaje escolar y familiar. Entre estos procesos se encuentran la atención, el control inhibitorio, la memoria de trabajo, la flexibilidad cognitiva, o el procesamiento fonológico (Lipina y SEgRetin 2015, 113).

\section{Conclusiones}

La epigénesis proactiva como propuesta teórica no ha estado carente de críticas. Algunos lanzan la pregunta de si deberíamos ser epigenéticamente proactivos (SCHLeim 2015), malentendiendo que la epigénesis proactiva se basa en una especie de intervención biogenética que puede tener efectos psicológicos secundarios. No tienen en cuenta que la gran ventaja de la epigénesis proactiva no reside en la vertiente biológica, sino más bien en la educativa; la posibilidad de descubrir que a través de la educación se puede proponer una

\footnotetext{
${ }^{3}$ La privación de condiciones de vida materiales y sociales durante los primeros seis mil días de vida producen serios impactos en la activación de redes neurales preferenciales. Las zonas más estudiadas al respecto han sido el sistema prefrontal ejecutivo (Lipina et al. 2013) y el temporal mnémico (FARAH et al. 2006).

${ }^{4}$ El Programa de Intervención Escolar implementado en la ciudad de Buenos Aires (Segretin et al. 20I4); el Programa Piloto de Estimulación Cognitiva (Segretin et al. 20 i4); el Programa Mate-Marote, implementado en la ciudad de Buenos Aires (Goldin et al. 20 I4); y el programa PCMC-A (Neville et al. 2013).
} 
simbiosis sociocultural y biogenética que se refleje en una huella epigenética almacenada en nuestros cerebros y que con el paso del tiempo afectará a las generaciones futuras, alumbra un camino muy importante.

Este camino es el de la educación, para que, a pesar de que en este momento estemos fraguados como xenófobos empáticos, precisamente debido a que somos evaluadores natos podamos elegir y educar en coherencia a esa elección la huella epigenética que modificada mediante el comportamiento, queremos legar a las generaciones futuras. Ese es el potencial ético y educativo de la epigénesis proactiva. La propuesta de K. Evers, a diferencia de otras, allana en este sentido un camino para un verdadero diálogo interdisciplinar entre la filosofía moral y las neurociencias, conjugando en su seno lo hermenéutico y lo empírico en el estudio de la moral humana, y haciendo hincapié en la autonomía y libertad del ser humano que, a través del proceso educativo, permita alcanzar un nivel moral a la altura de nuestro tiempo. ${ }^{5}$

${ }^{5}$ Este artículo se inserta dentro del proyecto de I+D+I del Ministerio de Economía y Competitividad titulado "Política, empresa y educación desde la neuroética aplicada" (FI2013-47136C2-2-P), que dirige D. García-Marzá. 


\section{BiBLIOGRAFÍA}

Bachelard, G. I953, Le Matérialisme rationnel, París: Presses Universitaires de France.

Bidon-Chanal, A. I996, "Reflexiones historiográficas sobre el 'Proyecto de una psicología para neurólogos' de S. Freud, en el centenario de su elaboración (1895-1995)", Revista de Historia de la Psicología, 17 (3-4): 256-62.

Cela-Conde, C. 2005, "Did Evolution Fix Human Values?", en Neurobiology of Human Values, J-P. Changeux, A. R. Damasio, W. Singer y Y. Christen (eds.), Berlín: Springer Verlag, 11-6.

Changeux, J.-P. i986, El hombre neuronal, Madrid: Espasa-Calpe.

Changeux, J.-P. 2004, The Physiology of Truth. Neuroscience and Human Knowledge, Londres: The Belknap Press of Hardvard University Press.

Changeux, J.-P. y Danchin, A. I976, "Selective stabilisation of developing synapses as a mechanism for the specification of neuronal netwoks", Nature, 264: 705-12.

Changeux, J.-P.; Courrège, P. y Danchin, A. I973, "A theory of the epigénesis of neural networks by selective stabilization of synapses", Proceedings of the National Academy of Science (USA), 70: 2974-8.

Churchland, P. S. 20 I 2, El cerebro moral. Lo que la neurociencia nos cuenta sobre la moralidad, Barcelona: Paidós.

Cortina, A. (ed.) 2o i2, Guia Comares de Neurofilosofia Práctica, Granada: Comares.

Cortina, A. 2007, Ética de la razón cordial. Educar en la ciudadanía del s. XXI, Oviedo: Nobel.

Cortina, A. 20 i i, Neuroética y neuropolitica. Sugerencias para la educación moral, Madrid: Tecnos.

Decety, J. 2007, "A social cognitive neuroscience model of human empathy", en Psychological Explanations of Social Behavior, E. HARMON-Jones y P. WinkiELMAN (eds.), Nueva York: Guilford, 246-70.

Dehaene, S. y Changeux, J.-P. I 989, "A simple model of prefrontal cortex function in delayed-response tasks", Journal of Cognitive Neuroscience, 1: 244-61.

Dehaene, S. y Changeux, J.-P. I991, "The Wisconsin card sorting test: Theoretical analysis and modeling in a neuronal network", Cerebral Cortex, 1: 62-79.

Dehaene, S.; Changeux, J.-P.; Naccache, L.; Sackur, J. y Sergent, C. 2006, "Conscious, preconscious, and subliminal processing: a testable taxonomy", Trends in Cognitive Neuroscience, 5.

Dehaene, S.; Dehaene-Lambertz, G. y Cohen, L. i998, "Abstract representations of numbers in the animal and human brain", Trends in Neuroscience, 21 (8): 355-611. 
Dehaene, S.; Sergent, C. y Changeux, J.-P. 2003, "A neuronal network model linking subjective reports and objective physiological data during conscious perception", Proceedings of the National Academy of Science USA, 100: 8520-5.

Edelman, G. M. I992, Bright air, brilliant fire. On the matter of the mind, Nueva York: Basic Books.

Evers, K. 2005, "Neuroethics: A Philosophical Challenge", The American Journal of Bioethics, 5 (2): 31-3.

doi: $10.1080 / 15265160590960302$.

Evers, K. 2007, "Toward a philosophy for neuroethics. An informed materialistic view of the brain might help to develop theoretical frameworks for applied neuroethics", EMBO reports (special issue), 8: 48-51.

Evers, K. 20 io, Neuroética. Cuando la materia se despierta, Madrid: Katz.

Evers, K. 201 5, "Can We Be Epigenetically Proactive?", en Open MIND, 13(T), T. Metzinger y J. M. Windt (eds), Frankfurt: MIND Group. doi: 10.15502/9783958570238.

Farah, M. J; Shera, D. M.; Savage, J. H.; Betancourt, L.; Gianetta, J. M., Brodsky, N. L. y Hurt, H. 2006, "Childhood poverty: specific associations with neurocognitive development", Brain Research, 1110: 166-74.

FlaCk, J. C. y De WAal, F. 2000, "Any animal whatever", Journal of Consciousness Studies, 7: 1-29.

Freud, S. I99I, Proyecto de una psicología para neurólogos y otros escritos. Madrid: Alianza.

García-Marzá, D. y Feenstra, R. (eds.) 20I 3, Ética y neurociencias: la aportación a la política, la economía y la educación, Castellón: Servei de Publicacions de la Universitat Jaume I.

Gazzaniga, M. S. 2006, El cerebro ético, Barcelona: Paidós.

Gibert, J. y Correa, B. 200 I, "La teoría de la autopoiesis y su aplicación en las ciencias sociales", Cinta moebio, 12: 175-93.

Goldin, A. P.; Hermida, M. J.; Shalom, D. E.; Elías Costa, M.; López-Rosenfeld, M.; Segretin M. S. y Sigman, M. 20i4, "Far transfer to language and math of a short software-based gaming intervention", Proceedings of the National Academy of Science USA, 111: 6443-8.

Gómez, C. 2007, "El ámbito de la moralidad: Ética y Moral", en La aventura de la moralidad, paradigmas, fronteras y problemas de la ética, C. GóMEz y J. MuGuerzA, (eds.), Madrid: Alianza, 19-54.

Gracia, D. 2013, "La insobornable libertad", en Bioética, Neuroética, Libertad y Justicia, F. J. López-Frías et al. (eds.), Granada: Comares, 551-79.

Greene, J. 2008, “The Secret Joke of Kant's Soul”, en Moral Psychology 3. The Neuroscience of Morality. Emotion, Brain Disorders, and Development, W. SINnot-Amstrong (ed.), Cambridge: MIT Press: 35-79. 
Greene, J.; Nystrom, L.; Engell, A.; Darley, J. y Cohen, J. D. 2004, "The Neural Bases of Cognitive Conflict and Control in Moral Judgment", Neuron, 44: 389-400.

Haidt, J. 200 I, "The Emotional Dog and Its Rational Tail”, Psychological Review, 108 (4): 814-34. doi: 10.1037//0033-295X.108.4.814.

Hare, R. M. I975, The Language of Morals, Oxford: Oxford University Press.

Iacobini, M.; Molnar-Szakacs, I.; Gallese, V.; Buccino, G.; Mazziotta, J. C. y Rizzolatti, G. 2005, "Grasping the intention of others with one's own mirror neuron system”, PLoS Biol, 3 (3): e79.

Jackson, P.; Brunet, E.; Meltzoff, A. y Decety, J. 2006, "Empathy examined through the neural mechanisms involved in imagining how I fell versus how you feel pain", Neuropsychologia, 44 (5): 752-61.

Koestler, A. 1989, The ghost in the machine, Londres: Arkana Books.

LeDoux, J. I999, The Emotional Brain. The Mysterious Underpinnings of Emotional Life, Londres: Phoenix.

Lipina, S. J. 20I4, "Consideraciones neuroéticas de la pobreza infantil", en $\mathrm{La}$ vida social del cerebro, A. SAlles y K. Evers (coord.), México D.F.: Fontamara, 67-101.

Lipina, S. J.; Segretin, M. S.; Hermida, M. J.; Prats, L.; Fracchia, C. y CoLомво, J. A. 20I3, "Linking childhood poverty and cognition: Individual and environmental predictors of non-verbal executive control in an Argentine simple", Developmental Science, 16: 697-707.

Lipina, S. J. y Segretin, M. S. 20 I 5, "6000 días más: evidencia neurocientífica acerca del impacto de la pobreza infantil”, Psicología Educativa, 21: 107-16.

Lorenz, K. I992, Sobre la agresión: el pretendido mal, México D.F.: Siglo XXI.

Maturana, H. y Varela, F. I984, El árbol del conocimiento: las bases biológicas del entendimiento humano, Santiago de Chile: Universitaria.

Mendez, M. 2006, "What frontotemporal dementia reveals about the neurobiological basis of morality", Medical Hypotheses, 67 (2): 411-8.

Moll, J.; Zahn, R.; Oliveira-Souza, R.; Krueger, F. y Grafman, J. 2005, “The neural basis of human moral cognition", Nature Reviews Neuroscience, 6: 799-809.

Moore, G. E. I978, Principia Ethica, Londres: Cambridge UP.

Mora, F. 2007, Neurocultura. Una cultura basada en el cerebro, Madrid: Alianza.

Neville, H. J.; Stevens, C.; Pakulak, E.; Bell, T. A.; Fanning, J.; Klein, S. y IsBeLL, E. 20I3, "Family-based training program improves brain function, cognition, and behaviour in lower socioeconomic status pre-schoolers", Proceedings of the National Academy of Sciences USA, 110: 12138-43.

Pallarés-Domínguez, D. 2013, "Críticas y orientaciones para el estudio en neuroética”, Recerca. Revista de Pensament i Anàlisi, 13: 85-102. 
Pedrol Troitero, R. 2009, "Comentario crítico sobre el concepto de autopoiesis y la concepción sobre la educación de Humberto Maturana”, Revista Semestral da Associação Brasileira de Psicologia Escolar e Educacional (ABRAPEE), 13 (2): 333-9.

Popper, K. I997, El cuerpo y la mente, Barcelona: Paidós. [Título original (1994). Knowledge and the body-mind problem. In defence of interaction, Londres y Nueva York: Routledge]

Popper, K. y Eccles, J. I993, El yo y su cerebro, Barcelona: Labor. [Título original (1977). The Self and Its Brain: an argument for interactionism Berlin: SpringerVerlag. Trad. cast. Solís Santos]

Ramachandran, V. S. 2008, Los laberintos del cerebro, Barcelona: La liebre de Marzo.

Ricoeur, P. 1992, Onseself as Another, Chicago: University of Chicago Press.

Rubia, F. J. 2009, El fantasma de la libertad. Datos de la revolución neurocientifica, Barcelona: Crítica.

SAnguineti, J. J. 2012, "El desafío antropológico de las neurociencias", Neurociencia, filosofía y teología. Conferencia Universidad Católica San Pablo, Arequipa, 3 de sept. de 2012.

Sanguineti, J. J. 20 I4, Neurociencia y filosofía del hombre, Madrid: Palabra.

Schelim, S. 2015, "Should we be Epigenetically Proactive? A commentary on Kathinka Evers", en Open MIND, 13(T), T. Metzinger y J. M. Windt (eds.), Frankfurt: MIND Group. doi: $10.15502 / 9783958570368$.

Segretin, M. S.; Lipina, S. J.; Hermida, M. J.; Sheffield, T. D.; Nelson, J. M.; Espy, K. A. у Colombo, J. A. 20 I4, "Predictors of cognitive enhancement after training in preschoolers from diverse socioeconomic backgrounds", Frontiers in Psychology, 5 (205).

Singer, T.; Seymour, B.; O’Doherthy, J. P.; Kaube, J.; Dolan, R. J. y Frith, C. D. 2004, "Empathy for pain involves the affective but not sensory components of pain”, Science, 303 (5661): 1157-62.

Sperry, R. W. I980, "Mind-Brain Interaction: Mentalism, Yes; Dualism, No", Neuroscience, 5: 195-206.

Tealdi, J. C. 20 2, “¿Qué es la neuroética?”, Cuadernos de ética, 27 (40): 1-9.

Torralva, T. y Manes, F. 20 I4, "Cognición social”, en La vida social del cerebro, A. Salles y K. Evers (coord.), México: Fontamara, 17-42.

Waddington, C. H. i942, "The epigenotype", Endevour, 18-20.

Wegner, D. M. 2002, The Illusion of Conscious Will, Cambridge MA: MIT Press. 
